\title{
PROJETO DE EXTENSÃO PIRILAMPOS: CONTAÇÃO DE HISTÓRIAS COM FANTOCHES
}

\author{
Ana Cláudia de Oliveira Freitas \\ UNEB \\ afreitas@uneb.br \\ Iolândia Silva Santos Araújo \\ UNEB \\ isarauio@uneb.br
}

\begin{abstract}
Resumo
Trata-se de um relato de experiência acerca das vivências e atividades desenvolvidas pela equipe do Projeto de extensão do Teatro de Fantoches Pirilampos ligado à Biblioteca e ao CEPAC (Centro de extensão e pesquisa artístico cultural) do Departamento de Educação Campus XII/ UNEB ao longo de seus 05 anos de existência. $O$ projeto surge por acreditar que através da contação de histórias com utilização de fantoches, além de proporcionar momentos movidos à fantasia, imaginação e arte, poderá despertar nas crianças o interesse pela leitura a partir de histórias diversas. Tem como público alvo alunos da rede municipal de ensino e privada da cidade de Guanambi-BA. Para execução do Projeto, foram selecionados graduandos do Curso de Pedagogia para atuarem como monitores, ressalvando que a seleção é aberta para discentes de todos os cursos. Os discentes foram, posteriormente, capacitados para manipular os bonecos bem como conduzir o show à frente do teatro, sendo importantes para futura atuação enquanto profissionais da educação. As atividades foram desenvolvidas tanto no espaço da Universidade quanto em escolas municipais, concentrando a maior parte no Campus XII, com vistas a oportunizar as crianças conhecerem o ambiente acadêmico. Em atendimento a 18 escolas, foram realizados 20 shows, contando com um público de 2.654 crianças. Acredita-se que esta atividade extensionista vem atingindo seu objetivo, pois além de resgatar a arte de contar histórias de forma contextualizada e lúdica, a Universidade cumpre parte de seu papel social com acomunidade.
\end{abstract}

Palavras-chave: Contação de histórias. Criança. Extensão. Escola.

\section{PIRILAMPOS EXTENSION PROJECT: STORYTELLING WITH PUPPETS}

\begin{abstract}
This is an experience report about the experiences and activities developed by the team of the Project of extension of the Theater of Puppets Pirilampos linked to the Library and CEPAC (Center for extension and cultural artistic research) of the Department of Education Campus XII/UNEB along of its 05 years of existence. The project arises from believing that through storytelling with the use of puppets, in addition to providing moments driven by fantasy, imagination and art, it can awaken children's interest in reading from diverse stories. Its target audience is students of the municipal teaching and private network of the city of Guanambi-BA. For the execution of the Project, were selected graduates of the Pedagogy Course to act as monitors, except that the selection is open to students of all courses. The students were then able to manipulate the dolls as well as conduct the show in front of the theater, being important for future performance as educational professionals. The activities were developed both in the University space and in municipal schools, concentrating most of the Campus XII, to make the children aware of the academic environment. In attendance to 18 schools,
\end{abstract}

Cidadania em Ação: Revista de Extensão e Cultura, Florianópolis (SC), v. 2, n.2, jul./dez. 2018. 
20 concerts were held, with an audience of 2,654 children. It is believed that this extensionist activity has reached its goal, because in addition to rescuing the art of storytelling in a contextualized and playful way, the University fulfills part of its social role with thecommunity.

Keywords: Storytelling. Child. Extension. School.

\section{PROYECTO DE EXTENSIÓN PIRILAMPOS: CUENTACUENTOS CON MARIONETAS}

\section{Resumen}

Se trata de un relato de experiencia acerca de las vivencias y actividades desarrolladas por el equipo del Proyecto de extensión del Teatro de Fantoches Pirilampos ligado a la Biblioteca y al CEPAC (Centro de extensión e investigación artístico cultural) del Departamento de Educación Campus XII / UNEB a lo largo de sus cinco años de existencia. El proyecto surge por creer que a través de la cuenta de historias con utilización de títeres, además de proporcionar momentos movidos a la fantasía, imaginación y arte, podrá despertar en los niños el interés por la lectura a partir de historias diversas. Tiene como público objetivo alumnos de la red municipal de enseñanza y privada de la ciudad de Guanambi-BA. Para la ejecución del Proyecto, fueron seleccionados graduandos del Curso de Pedagogía para actuar como monitores, resalvando que la selección es abierta para alumnos de todos los cursos. Los discentes fueron posteriormente capacitados para manipular los muñecos así como conducir el show al frente del teatro, siendo importantes para futura actuación como profesionales de la educación. Las actividades fueron desarrolladas tanto en el espacio de la Universidad como en escuelas municipales, concentrando la mayor parte en el Campus XII, con vistas a oportunizar a los niños conocer el ambiente académico. En atención a 18 escuelas, se realizaron 20 shows, contando con un público de 2.654 niños. Se cree que esta actividad extensionista viene alcanzando su objetivo, pues además de rescatar el arte de contar historias de forma contextualizada y lúdica, la Universidad cumple parte de su papel social con la comunidad.

Palabras clave: Cuenta de historias. Niño. Extensión. Escuela.

Cidadania em Ação: Revista de Extensão e Cultura, Florianópolis (SC), v. 2, n.2, jul./dez. 2018. 


\section{PRIMEIROS MOVIMENTOS}

O presente estudo se propõe a discorrer sobre as experiências vividas no Projeto de Extensão Teatro de Fantoches Pirilampo, desenvolvido no âmbito do Departamento de Educação - Campus XII da Universidade do Estado da Bahia, situado no município de Guanambi. Entretanto, para a compreensão dessa ação se faz necessário situar o leitor em nossas incursões extensionistas no Campus XII.

Em 2006 o CEPAC (Centro de extensão e pesquisa artístico cultural) foi fundado e se mantém em atividade até o presente momento, com o objetivo maior de promover e apoiar atividades artístico culturais no Departamento, seja em sua sede, na comunidade ou em outros espaços; em forma de apresentações, estudos ou formação. Esse Centro, coordenado pela professora de Artes do Departamento, Prof ${ }^{a}$ Ana Cláudia, já abrigou e abriga diversas ações, a saber: grupos de teatro, dança e canto coral, oficinas de qualificação docente em artes, grupos de estudos em artes e o Teatro de Fantoches Pirilampos, objeto deste relato.

Em 2012, a UNEB recebeu da coordenadora do CEPAC a doação do Teatro de Fantoches Pirilampos, que é composto de estrutura/palco de madeira, iluminação, 2 cenários/panôs, 3 jogos de cortinas, 39 fantasias e 59 fantoches de luva.

Figura 1: Teatro de fantoches.

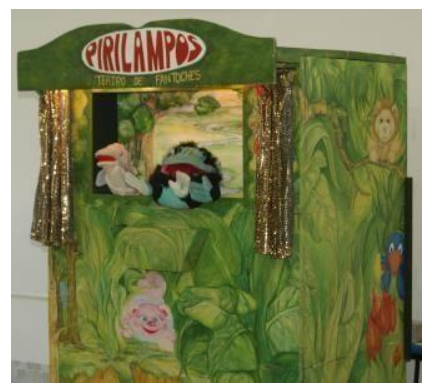

Fonte: arquivo pessoal das autoras.

Durante dois anos todo o material ficou devidamente armazenado nas instalações do CEPAC, sem estrutura organizacional para ser implantado, até que em 2014 a Analista Universitária e Pedagoga Iolândia Silva Santos Araújo, assume a Coordenação da Biblioteca do Campus e propõe estruturar o Teatro de Fantoches como um projeto de extensão, dessa forma passaria a estar ligado à Biblioteca do Campus e ao CEPAC.

Cientes de que a contação de histórias é uma arte milenar que convida à leitura, indo muito além do prazer sentido e expressado, afinal, por meio de histórias contadas as crianças podem ampliar o vocabulário, desenvolver a confiança, o imaginário e o pensamento

Cidadania em Ação: Revista de Extensão e Cultura, Florianópolis (SC), v. 2, n.2, jul./dez. 2018. 
hipotético, é que implantamos o Projeto Pirilampos, coordenado em sua estrutura administrativa pela Analista Iolândia e em sua estrutura artística pela Professora Ana Cláudia.

Com a leitura ou com a escuta de uma história o sujeito é convidado a viajar sem sair do lugar, desvendando assuntos e embarcando numa aventura incrível que só se torna possível com a satisfação prazerosa e com intervenção pedagógica, a fim de estimular a imaginação de forma lúdica. Como aponta Abramovich (1991, p.17):

É ouvindo histórias que se pode sentir "também" emoções importantes, como a tristeza, a raiva, a irritação, o bem-estar, o medo, a alegria, o pavor, a insegurança, a tranquilidade, e tantas outras mais, e viver profundamente tudo que as narrativas provocam em quem as ouve, toda amplitude e significâncias e verdade que cada uma faz ou não brotar [...], pois é ouvir sentir e exercer com olhos do imaginário.

Toda história, por mais simples que pareça consegue transmitir sensações significativas para o sujeito que a ouve. Tendo em vista que as crianças em geral, tem muito interesse por narrativas diversas, ao proporcionar um espaço de contação de história e inserir os discentes, preferencialmente do curso de pedagogia, capacitando-os para o desenvolvimento dessa atividade, e por considerar essa experiência relevante para formação profissional e acadêmica desses estudantes, bem como possibilitar à comunidade externa que muitas vezes não tem a oportunidade de presenciar e viver momentos como esse em outros espaços; e conscientes do compromisso social que a Universidade possui enquanto Instituição Pública, esse projeto visa incentivar o hábito da leitura e o desenvolvimento do gosto por ler, ao criar momentos de contação de histórias através do Teatro de Fantoches Pirilampos.

A realização de atividades de contação de histórias no ambiente da Biblioteca Pública permite a concretização da primeira de suas "missões-chave", preconizadas no Manifesto sobre as Bibliotecas Públicas da United Nation Educational, Scientific and Cultural Organization (Organização para a Educação, a Ciência e a Cultura das Nações) - UNESCO (1994): "Criar e fortalecer os hábitos de leitura nas crianças, desde a primeirainfância".

Figura 2: Show apresentado em uma escola municipal em 2015.

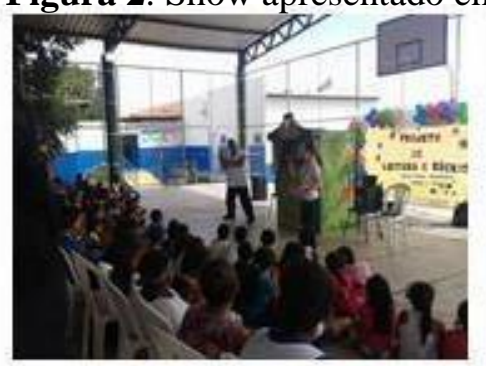

Fonte: Arquivo pessoal das autoras

Assim, promover o hábito da leitura prazerosa e, ao mesmo tempo, proporcionar às

Cidadania em Ação: Revista de Extensão e Cultura, Florianópolis (SC), v. 2, n.2, jul./dez. 2018. 
crianças da creche, educação infantil e dos anos iniciais do ensino fundamental das Escolas Públicas e Privadas do município de Guanambi um momento movido a fantasia, imaginação e arte, se torna nosso principal objetivo ao desenvolver esse projeto.

Para tanto, iniciamos nossa jornada a partir da organização interna, descrita na seção "Bastidores", para, em seguida, ir ao público, experiência apresentada na seção "A cena se abre", em "De volta aos bastidores" refletimos a experiência vivida por nós e pelas crianças, assim como projetamos os próximos movimentos.

\section{BASTIDORES}

Para que se possa realizar atividades de cunho extensionista no âmbito da universidade, algumas ações prévias se fazem necessárias, assim registramos o projeto no SIP - Sistema Integrado de Planejamento da instituição e, após aprovação, demos continuidade às ações, agora oficialmente.

Então, iniciamos a composição de uma equipe de trabalho para operar o teatro. São necessários dois manipuladores - que serão os responsáveis pelas entradas, falas e interpretações dos bonecos que compõem a história, um apresentador - que media o contato dos fantoches com o público e um assistente que irá operar o som. Realizou-se a divulgação e abertura de inscrições para monitoria voluntária através do NUPEX - Núcleo de Apoio a Pesquisa e Extensão. Concluído o período de inscrições, foi feita a seleção dos discentes inscritos; processo realizado através de entrevista oral, em que pontos considerados importantes para a seleção de monitor foram abordados pela coordenação. Após divulgação da lista com os nomes dos/as alunos/as selecionados/as para atuarem como monitores voluntários, foram realizadas reuniões para expor os objetivos do projeto, apresentar as atividades pensadas, ler histórias já produzidas para o teatro, ouvir algumas músicas que poderiam compor o repertório dos shows. Também, apresentar a estrutura do Teatro, assim como praticar sua montagem, ter contato com os bonecos existentes e treinar a manipulação, criar histórias e organizar a sequência dos fantoches, enfim, vários encontros foram realizados com o intuito de montar histórias e ensaiá-las para serem apresentadas. É importante mencionar que o conteúdo de tais histórias varia a cada ano, pois um show organizado e ensaiado será apresentado para o maior número de escolas possíveis durante o ano vigente.

Estando todo o show pronto e ensaiado, é hora de contatar o público. Nesse momento, a Universidade vai à comunidade levando o conhecimento produzido. Em contato com a

Cidadania em Ação: Revista de Extensão e Cultura, Florianópolis (SC), v. 2, n.2, jul./dez. 2018. 
Secretaria de Educação do Município e, posteriormente, agendamos com as diretoras das escolas as apresentações, hora o show indo até a escola, hora a escola vindo até a Universidade. Pensamos que os dois movimentos são importantes, e procuramos articulá-los da melhor maneira possível. A prefeitura fornece o transporte para deslocamento dos manipuladores e da estrutura do teatro às escolas ou das crianças até o Campus. Em qualquer das duas situações, quando a cena se abre..., a experiência é exuberante.

\section{A cena se abre}

O show se estrutura num primeiro momento em que o apresentador, por meio de conversa e música, prepara as crianças para receberem os fantoches, assim, os primeiros bonecos são apresentados para o público saindo do teatro e indo até as crianças, dessa forma elas já ficam cientes de que são pessoas que ali estão, evitando situações de pânico, principalmente para as muito pequenas.

Figura 3: Apresentação dos bonecos.
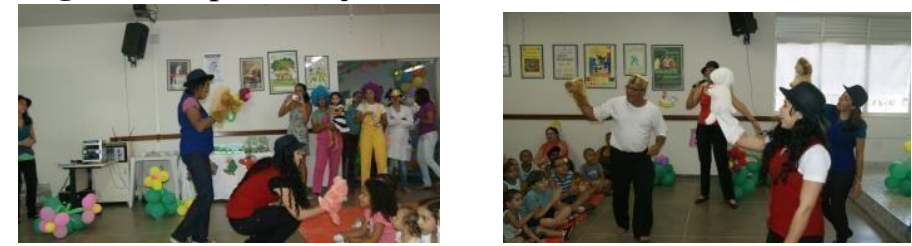

Fonte: Arquivo pessoal das autoras.

Passamos então para o momento em que os fantoches aparecem em grupos de personagens conhecidos, estimulamos aí a memória, incentivando-os a lembrarem de personagens de revistas em quadrinhos e desenhos. As crianças cantam e se encantam com os personagens que fazem parte de seu universo infantil; iniciamos aqui também a utilização de fantasias que são colocadas nos participantes.

Figura 4: Crianças caracterizadas.

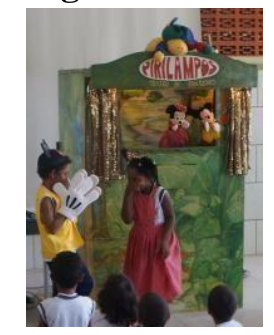

Fonte: Arquivo pessoal das autoras.

Cidadania em Ação: Revista de Extensão e Cultura, Florianópolis (SC), v. 2, n.2, jul./dez. 2018. 
Passamos então a momentos mais direcionados aos ensinamentos práticos como pentear os cabelos e escovar os dentes, dentre outras ações importantes relacionadas à educação e convívio.

Figura 4: Interação dos/as alunos/as com os bonecos.

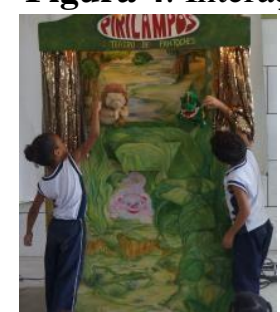

Fonte: Arquivo pessoal das autoras.

Alguns relatos informais são muito interessantes em relação à figura acima; mães já nos interpelaram para agradecer, uma vez que depois do teatrinho seu filho não deixava mais de escovar os dentes, com medo de ficar com dor de dentes como o jacaré. Esse relato já nos aponta um viés da valia desse projeto, pois como afirma Coelho (1989, p.12), “[...] a história aquieta, serena, prende a atenção, informa, socializa, educa. [...] a história é importante alimento da imaginação".

Relembrando os famosos contos de fadas e fábulas, convidamos algumas crianças para se fantasiarem e nos ajudarem a contar histórias conhecidas para os demais coleguinhas. Assim, fantasiadas, na quantidade que for necessária para a contação da história, nos ajudam interpretando personagens como Branca de Neve, Alladin, Alice no País das Maravilhas e outras.

Figura 5: Crianças vestidas dos personagens.

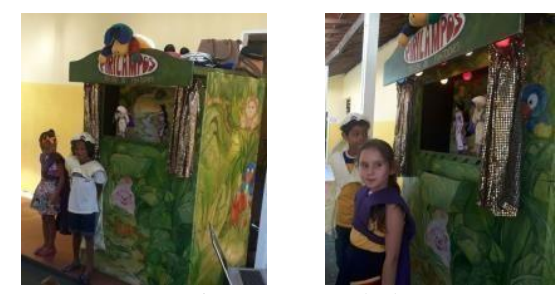

Fonte: Arquivo pessoal das autoras.

Finalizando o show, apresentamos uma história autoral ou adaptada a partir de uma outra ou tema que se queira trabalhar na escola. Nesse momento damos maior atenção a temas como confiança, perdão, acessibilidade, respeito.

A apresentação tem 45 minutos de duração e as crianças participam atentas e empolgadas o tempo todo. Elas conversam com os fantoches, se fantasiam, interpretam, dão risadas e até se assustam; nos ajudam a tornar as histórias mais instigantes e prazerosas. Os

Cidadania em Ação: Revista de Extensão e Cultura, Florianópolis (SC), v. 2, n.2, jul./dez. 2018. 
professores que acompanham também são estimulados a participar e contribuem significativamente com o êxito dos shows.

Em 5 anos de existência desse projeto, em 2016 por questões internas da universidade não foram desenvolvidas atividades, mas nos demais anos atendemos a comunidade conforme se verifica no quadro 1 .

Quadro 1: quantitativo de escolas e público atendido de 2014 a 2017.

\begin{tabular}{|c|c|c|c|c|}
\hline \multirow{2}{*}{ Ano } & \multicolumn{4}{|c|}{ Quantidade de } \\
\cline { 2 - 5 } & $\begin{array}{c}\text { Alunos/Monitores que } \\
\text { integraram o projeto }\end{array}$ & Escolas atendidas & Shows realizados & $\begin{array}{c}\text { Crianças que assistiram } \\
\text { aos shows }\end{array}$ \\
\hline 2014 & 4 & 1 & 2 & 220 \\
\hline 2015 & 8 & 4 & 7 & 1.084 \\
\hline 2017 & 11 & 13 & 11 & 1.350 \\
\hline
\end{tabular}

Fonte: Relatórios anuais do projeto.

Para compreender melhor os dados apresentados acima, é importante saber que no ano de 2014, com a implantação do projeto e após a seleção de alunos/monitores, nós entramos em contato com a Secretaria Municipal de Educação e recebemos a indicação de duas escolas para realização do show, ao final da negociação com as diretoras, apenas uma escola pode participar da atividade. A Secretaria disponibilizou o transporte para as crianças virem até a universidade e fizemos 02 shows, um no turno matutino e outro no turno vespertino.

No ano de 2015 reabrimos as inscrições para monitoria, os alunos que já faziam parte do grupo decidiram continuar e mais 04 passaram a integrar a equipe, o que nos deu mais mobilidade, pois os grupos se revezaram nas apresentações. Como um dos integrantes era monitor do PIBID (Programa Institucional de Bolsa de Iniciação à Docência) nos foi proposto por ele que o projeto estabelecesse uma parceria com as escolas onde funcionam o PIBID, sendo a sugestão acatada por todas/os. Após algumas reflexões sobre possíveis temas a serem trabalhados nas histórias, optamos por realizar a leitura do livro "Xangô, o trovão", escrito por Reginaldo Prandi (2003), que aborda a cultura e a religião dos africanos. Dentre as várias histórias existentes no livro, foi escolhida a seguinte: Como o rei de Ejibô passou a se chamar papa-purê-de-inhame. Fez-se a adaptação necessária e, nessa proposta, decidimos que o show iria até as escolas, assim organizamos a agenda e foram feitas as apresentações para as crianças da educação infantil e ensino fundamental I e, embora não seja nosso público alvo, também apresentamos para alunos do ensino fundamental II.

No ano de 2017 a Secretaria de Educação do Município nos procurou solicitando o

Cidadania em Ação: Revista de Extensão e Cultura, Florianópolis (SC), v. 2, n.2, jul./dez. 2018. 
projeto; reabrimos as inscrições para monitoria, realizando a seleção de novos monitores, o que foi possível formar 03 equipes. Decidimos solicitar à prefeitura que trouxesse os alunos até a Universidade priorizando os estudantes da educação infantil e fundamental I, já que o formato do projeto se direciona a esse público. Durante uma semana pudemos movimentar a UNEB com a circulação intensa de crianças das escolas municipais; foram realizados 11 shows distribuídos nos turnos matutino e vespertino, durante 05 dias no mês de outubro. $\mathrm{O}$ resultado foi muito bom e, ao final das atividades, já fomos solicitados para organizar no ano de 2018 nova produção, mas que pudéssemos, desta vez, também ir aos 03 distritos de Guanambi e às creches, pois esses espaços desejavam ser contemplados, mas o deslocamento deles para a Universidade exige uma logística mais delicada.

\section{De volta aos bastidores}

Ao analisar a trajetória do Teatro de Fantoches Pirilampos, no âmbito da Universidade, como projeto dedicado a despertar o gosto pela leitura, mas também pela arte dos fantoches, não podemos concluir nada além de que esta é uma experiência ímpar e necessária, gratificante e extraordinária.

O projeto enfrenta dificuldades naturais, porém completamente contornáveis como, por exemplo, o fluxo dos estudantes. É natural que a cada ano as equipes de trabalho sejam alteradas, primeiramente para dar oportunidade a todos, assim como pelas exigências de cada período de estudo que estreita o tempo do estudante aumentando suas atividades acadêmicas. E, se por um lado a rotatividade é positiva pela oportunidade gerada, por outro entrava o andamento dos shows, pois a manipulação de bonecos e a construção de histórias são atividades artísticas que exigem dedicação, conhecimento e muito trabalho. O que encaramos é o contínuo recomeço, o que demanda tempo de apropriação da arte da manipulação. É interessante observar o orgulho e carinho dos alunos que já passaram pelo projeto ao se referirem a ele, ao recomendarem o show pelos espaços educativos que percorrem e aos estudantes que chegam para participar da equipe. Sendo os colaboradores alunos do curso de Pedagogia, consideramos que as ações deste Projeto são relevantes, uma vez que proporcionam aos graduandos, através da adaptação, criação, contação de histórias e apresentação dos espetáculos, desenvolver e/ou aprimorar o seu lado lúdico e criativo, podendo essas experiências ter impactos positivos em sua atuação enquanto futuros profissionais da educação.

No que se refere à parceria da Universidade e Secretaria de Educação/Escolas,

Cidadania em Ação: Revista de Extensão e Cultura, Florianópolis (SC), v. 2, n.2, jul./dez. 2018. 
acreditamos que a partir do momento em que a Universidade se aproxima desses espaços através de ações extensionistas, colocando a serviço da comunidade seus recursos humanos e materiais, tornando público o conhecimento produzido pela instituição, estamos cumprindo um relevante papel social. É notório, pelo passar dos anos, o reconhecimento da comunidade escolar em relação à valia da ação, pois a cada ano temos atendido mais escolas, nos deixando mais próximos do nosso objetivo que é estar em 100\% das instituições públicas e particulares, valendo a resalva de que ainda não foi possível adentrar aos espaços privados de educação por questões de organização e priorização da rede pública, cujo público, certamente tem menos acesso que os demais.

Para além da parceria, percebemos algumas questões que merecem atenção durante as apresentações, alusivo ao local de instalação e acomodação do teatro e da plateia. Percebemos que o conforto quando apresentamos na UNEB, para todos os envolvidos, integrantes e plateia, é muito melhor. No Departamento dispomos de uma ampla sala, com som e ar condicionado (nossa cidade é muito quente), o show fica montado sem a necessidade de desmontá-lo de uma apresentação para outra, e as crianças se encantam quando se deslocam de suas unidades para a Universidade. Também consideramos importante que o público escolar vivencie mais nosso espaço universitário; acreditamos que este convívio tornará mais natural o desejo de futuramente fazerem parte desse ambiente. Nos relatos informais das professoras, também há uma preferência pelo deslocamento até a instituição universitária, pois este permite trabalhar, além da diversão e proposta cênica do teatro, diversas questões comportamentais e espaciais, agregando, ainda mais valor à ação educativa, pensando que fica mais direcionado ao público alvo, em relação à faixa etária, a que se destina o projeto. Quando vamos às escolas, temos que nos adaptar ao espaço existente, o que não diminui a qualidade do trabalho, mas nos colocamos no pátio, por vezes lugares abertos expostos ao vento, sol e calor. Outra questão, é que o show acaba por interferir nas aulas de turmas maiores, o que leva a escola a paralisar as atividades destas. Diante esta percepção, damos prioridade em trazer as escolas até a Universidade, sempre que possível.

Por fim, vale relatar a participação das crianças que ficam os 45 minutos dos shows atentas e participativas. É especial perceber o envolvimento; os olhos delas brilham encantadas com as histórias.

Diante o exposto, pode-se afirmar que a contação de histórias através de fantoches pode ajudar as crianças em suas descobertas, pois os personagens as propiciam vivências únicas, capazes de abrir portas de um novo mundo para visões de imenso prazer,

Cidadania em Ação: Revista de Extensão e Cultura, Florianópolis (SC), v. 2, n.2, jul./dez. 2018. 
transformando e se deixando transformar por meio da imaginação. Espera-se que a realização desse projeto venha contribuir e incentivar que prática de contar histórias, bem como outras ações lúdicas sejam realizadas constantemente pelos professores no ambiente escolar, não se limitando apenas às atividades extensionistas desenvolvidas eventualmente nesses espaços.

Cidadania em Ação: Revista de Extensão e Cultura, Florianópolis (SC), v. 2, n.2, jul./dez. 2018. 


\section{REFERÊNCIAS}

ABRAMOVICH, F. Literatura infantil: Gostosuras e bobices. 2.ed. São Paulo: Scipione, 1991. $17 \mathrm{p}$.

COELHO, B. Contar histórias: uma arte sem idade. 2.ed. São Paulo: Ática, 1989. 12 p.

JOLIBERT, J. (org.). Formando crianças leitoras V.1. Porto Alegre: Artmed, 1994.

MARTINS, M. H. O que é leitura. 19.ed. São Paulo: Brasiliense, 2007.

ORGANIZAÇÃO DAS NAÇÕES UNIDAS PARA A EDUCAÇÃO, A CIÊNCIA E A CULTURA. Manifesto da IFLA/UNESCO sobre as Bibliotecas Públicas, 1994.

Disponível em: http://snbp.culturadigital.br/manifestos/manifesto-da-unesco-sobrebibliotecas-publicas/. Acesso em: 01 abr. 2018.

PRANDI, R. Xangô, o trovão: outras histórias dos deuses africanos que vieram ao Brasil com os escravos. São Paulo: Companhia das Letras, 2003.

Cidadania em Ação: Revista de Extensão e Cultura, Florianópolis (SC), v. 2, n.2, jul./dez. 2018. 